\title{
Shear Stability and Thickening Properties of Homo and Copolymer of Methyl Methacrylate
}

\author{
Pranab Ghosh *, Tapan Das, Debabrata Nandi
}

Natural Product and Polymer chemistry Laboratory, Department of Chemistry, University of North Bengal, Darjeeling, 734013, India

\begin{abstract}
The degradation stability towards mechanical shearing (shear stability) of poly(methyl methacrylate) (PMMA) and its copolymer with styrene at different level of concentrations have been investigated. With a view to understanding the relationship between the thickening performance (percent increase in viscosity of the solvent in the additive of the unit weight of polymers) and shear stability of the polymer, the thickening abilities of the polymer were also determined and compared. Pour point depressant properties of the copolymers in comparison to the homopolymer were also tested in different base stocks.
\end{abstract}

Keywords Viscosity Index, Shear Stability, Thickening Power

\section{Introduction}

Polymer containing fluids exhibit less reduction in viscosity with increase in temperature than the corresponding base fluids containing no polymer. The hydrodynamic volume of the polymer in the fluid increases with increase in temperature thereby resulting in an increase in viscosity, which greatly compensates the opposing effect of commonly observed reduction in viscosity of a fluid with rise in temperature. In the fields of lubricants, the degree of susceptibility of viscosity of a fluid to temperature variations is quantitatively expressed by an empirical term known as viscosity index (VI). A higher VI value signifies a lesser effect of temperature on viscosity. Polymers employed as additives in lubricants to enhance the VI (i.e. to minimize the temperature dependency of viscosity) are called as viscosity index improvers (VII) or viscosity modifiers (VM) [1-3] and corresponding VII - treated lubricants are categorized as multigrade oils as opposed to monograde oils which contain no VI improvers. Several kinds of polymers, such as poly(methyl methacrylate) (PMMA), olefin copolymer (OCP) and hydrogenated styrene-diene copolymer (SDP) are generally used as VMs in lubricating oil compositions.

Shear stability of the VM is one of the important criteria that determine its suitability in a lubricant formulation. The shear stability of the doped additive has strong influence on multigrade engine oil's ability to retain its viscosity under shearing conditions, experienced by the lubricant while in use. The loss of viscosity of a lubricant under shear can be

* Corresponding author: pizy12@yahoo.com (Pranab Ghosh) Published online at http://journal.sapub.org/ajps Copyright (C) 2011 Scientific \& Academic Publishing. All Rights Reserved two kinds, namely a temporary viscosity loss (TVL) or a permanent viscosity loss (PVL)[4-6]. The PVL values are more frequently expressed in terms of permanent shear stability index (PSSI) $[7,8]$ using the equations,

$$
\begin{aligned}
& \operatorname{PVL}(\%)=\left(\mathrm{V}_{\mathrm{i}}-\mathrm{V}_{\mathrm{s}}\right) / \mathrm{V}_{\mathrm{i}} \times 100 \\
& \operatorname{PSSI}=\left(\mathrm{V}_{\mathrm{i}}-\mathrm{V}_{\mathrm{s}} / \mathrm{V}_{\mathrm{i}}-\mathrm{V}_{0}\right) \times 100
\end{aligned}
$$

Where $\mathrm{V}$ refers to kinematic viscosity $(\mathrm{KV}), \mathrm{V}_{0}=\mathrm{KV}$ of the solvent before addition of polymer, $\mathrm{V}_{\mathrm{i}}=$ Initial $\mathrm{KV}$ of the solvent with polymer, $\mathrm{V}_{\mathrm{s}}=\mathrm{KV}$ of the solvent after shearing.

A detailed study of the literature indicated that only a few investigations have so far been carried out on the effects of lubricant compositional parameters such as polymer type, polymer concentration, base oil viscosity, etc. on the shear stability performance of multigrade lubricants. Polymers of alkyl methacrylate used as additives in lubricant composition for improving the viscometric and rheological properties of the lubricant[9-12]. They also looked upon to provide additional performance characteristic such as improved low temperature fluidity and dispersancy. Although poly(alkyl methacrylates) (PAMAs) are preferred type of additives in certain application, they often contribute to enhance formation of deposits in the engine due to thermal instability of these additives under high temperature conditions. Approach to overcome this shortcoming is always associated with a risk of affecting certain beneficial properties associated with normal poly(alkyl methcrylates), such as pour point depressant (PPD) and good shear stability. Therefore, the recent research on methacrylate additives has been concerned on copolymer of methacrylates with various stabilizing monomer.

It is well known that inclusion of styrene in the composition of an additive increases the resistance of the co polymer compounded oil to the action of heat. Since homopolymer of styrene is insoluble in lube oil they are introduced in the 
composition of oil soluble polymer by copolymerization which may be useful as a PPD / VM (Viscosity modifier) for petroleum and synthetic oil.

Thus, as a part of our ongoing studies on lube oil additives $[1,2]$, studies were undertaken in this area with a view to arriving at possible generalization on the effects of different level of concentration, of the copolymer of MMA - styrene on shear stability as well as on the pour point depressant performance of the additives. In this investigation, shear stabilities of the homopolymer of MMA and four of its copolymer with styrene $(2.5$ to $10 \%, \mathrm{w} / \mathrm{w})$ taken in toluene were determined in terms of kinematic viscosity and as per the standard ASTM method. The prepared additives were also evaluated as pour point depressant using base oils collected from two different sources through the standard ASTM test method. The observations have been co-related with the homopolymer towards arriving at possible generalization on this effect.

Oil thickening property of the polymer, which is a direct measure of percent increase in the viscosity of the base stocks for addition of its unit amount of weight has also been investigated and reported here. This property can also be taken as the extent of interaction of the polymer with the base stock, greater the thickening property; greater is the extent of interaction[1]. Fuel economy may also be predicted by the thickening power of a lube oil additive.

All the polymers were synthesized by following the method as reported earlier[2] and characterized on the basis of spectral analysis (IR, NMR), thermo gravimetric analysis (TGA) and viscometric method.

The shear stability of the polymer solutions in toluene was determined in terms of kinematic viscosity and as per the standard ASTM method. During the investigation, the type and concentration of the VMs, effect of styrene incorporation in the copolymer, effect of intrinsic viscosity / polymer molecular weight on their PSSI were evaluated and the results are being reported here.

\section{Experimental}

\subsection{Polymerization}

The polymerization was carried out in a four necked round bottom flask equipped with a stirrer, condenser, thermometer, an inlet for the introduction of nitrogen and a dropping funnel through which to add styrene drop wise. In the flask was placed desired mass of Methyl methacrylate (MMA) and initiator benzoyl peroxide (BZP) followed by the desired mass of styrene was added drop wise for $2 \mathrm{~h}$ in the presence of toluene as solvent. The reaction temperature was maintained at $353 \mathrm{~K}$ for $6 \mathrm{~h}$. At the end of the reaction time, the reaction mixture was poured into methanol with stirring to terminate the polymerization and precipitate the polymer. The polymer was further purified by repeated precipitation of its hexane solution by methanol followed by drying under vacuum at $313 \mathrm{~K}$. A homopolymer of MMA was similarly prepared and purified under the same conditions for use in reference experiments.

\subsection{Measurement}

IR spectra were recorded on a Shimudzu FT-IR 8300 spectrometer using $0.1 \mathrm{~mm} \mathrm{KBr}$ cells and the spectra were recorded at room temperature within the wave number range 400 to $4000 \mathrm{~cm}^{-1}$. NMR spectra were recorded in Brucker Avance $300 \mathrm{MHz}$ FT-NMR spectrometer using $5 \mathrm{~mm}$ BBO probe. $\mathrm{CDCl}_{3}$ was used as solvent and TMS as reference material.

\subsection{Viscometric Measurements}

Viscometric properties were determined at $313 \mathrm{~K}$ in toluene solution, using an Ubbelohde OB viscometer (having viscometer constant values are $\mathrm{K}^{\prime}=0.00268 \mathrm{~cm}^{2} / \mathrm{sec}^{2}, \mathrm{~L}=$ $-19.83 \mathrm{~cm}^{2}$ and volume of the bulb is $3 \mathrm{~cm}^{3}$ and length of the capillary $11.3 \mathrm{~cm}$ ). Experimental determination was carried out by counting time flow at least nine different concentrations (ranging from 0.2175 to $0.0870 \mathrm{~g} \cdot \mathrm{cm}^{-3}$ ) of the sample solutions. The time flow of the solution was manually determined by using a chronometer. In a single measurement the lowest value of solution concentration was chosen for the calculation. The viscometer was calibrated frequently with distilled water. The viscosity results were checked against viscosity of known solutions and accuracy was found to be nearly $0.2 \%$. Precautions regarding prevention of evaporation of solvent were taken in all the cases. Intrinsic viscosity and viscometric mol. weight were determined (Table 2) by using the experimental viscosity of the polymer solutions in Huggins (eq.1) and Mark Houwink equation[2](eq.2) respectively.

$$
\eta_{\mathrm{sp}} / \mathrm{C}=[\eta]_{\mathrm{h}}+\mathrm{k}_{\mathrm{h}}[\eta]_{\mathrm{h}}{ }^{2} \mathrm{C}
$$

Where, $\mathrm{C}$ is mass concentration.

$\eta_{\mathrm{sp}}=\eta_{\mathrm{r}}-1$, specific viscosity

$\eta_{r}=t / t_{0}$, relative viscosity or viscosity ratio (where $t$ is time flow of solution and $t_{0}$ is time flow of pure solvent).

$[\eta]_{\mathrm{h}}=$ intrinsic viscosity, respective to Huggins equation, $\mathrm{k}_{\mathrm{h}}$ Huggins coefficients

$$
[\eta]=\mathrm{K} \mathrm{M}^{\mathrm{a}}
$$

where $[\eta]$, the intrinsic viscosity, can be calculate by using Huggins equation, parameter ' $K$ ' and ' $a$ ' depends on the type of polymer, solvent, and temperature. For the viscosity average molecular weight determination, the constants $\mathrm{K}=$ $0.00387 \mathrm{dl} / \mathrm{g}$ and $\mathrm{a}=0.725$ were employed in Mark Houwink - Sukurda relation[13,14].

\subsection{Evaluation of Prepared Additive as Pour Point Depressants in Base Oils}

The prepared additives were evaluated as pour point depressant using base oils collected from two different sources $\mathrm{A}$ and $\mathrm{B}$, through the pour point test according to the ASTM-D-97 method using WIL-471 cloud and pour point test apparatus model 3 (India). The effect of additive concentration was investigated by using different doping concentration. The experimental data were noted by taking an 
average of three experimental results under identical conditions.

\subsection{Shear Stability}

Tests were conducted as per ASTM D- 3945 method and kinematic viscosity of fresh toluene and sheared polymer solution in toluene was determined by ASTM D- 445 and D-4741 procedure respectively.

\section{Results and Discussion}

\subsection{Spectroscopic Analysis}

IR spectra of the homo polymer showed a peak at $1732 \mathrm{~cm}^{-1}$ due to the presence of ester carbonyl group stretching vibration. The broad peak ranging from 1260 to $1000 \mathrm{~cm}^{-1}$ appeared owing to the ester C-O stretching vibration along with broad band from 950 to $650 \mathrm{~cm}^{-1}(\mathrm{C}-\mathrm{H}$ bending) and from 3100 to $2900 \mathrm{~cm}^{-1}$ due to presence of stretching vibrations. The existence of copolymer was confirmed by IR and NMR analysis. Carbonyl stretching vibration at $1732 \mathrm{~cm}^{-1}$ of the homo polymer shifted to $1720 \mathrm{~cm}^{-1}$ in the copolymer. Peaks at $760 \mathrm{~cm}^{-1}$ and $697 \mathrm{~cm}^{-1}$ were attributed to the $\mathrm{C}-\mathrm{H}$ bond of the phenyl group of styrene. In its ${ }^{1} \mathrm{H}$ NMR spectra the copolymer indicated the presence of phenyl group at $7.2 \mathrm{ppm}$ and the $-\mathrm{OCH}_{2}$ group from the acrylate at $3.9 \mathrm{ppm}$. The extent of incorporation of styrene in the polymer chain (Table1) was determined through a comparison of area of $-\mathrm{OCH}_{2}$ group at $3.9 \mathrm{ppm}$ in the area of signal due to phenyl protons at 7.2ppm based on earlier reports[15] as well as on the basis of our earlier paper which was further verified through an analysis of FT-IR spectral data following a method as also discussed in our earlier paper[1].

Table 1. Composition of the monomers in the co polymers in terms of mass fraction determined by PMR and FT-IR spectro photometric method. $\mathrm{P}-1$ is homopolymer of Methyl methacrylate (MMA); P-2 to P-5 are the copolymer of MMA + different mass fractions of styrene

\begin{tabular}{|c|c|c|c|c|}
\hline \multirow{2}{*}{$\begin{array}{c}\text { Polymer } \\
\text { sample }\end{array}$} & \multicolumn{2}{|c|}{$\begin{array}{c}\text { Mass fraction in the } \\
\text { feed }\end{array}$} & \multicolumn{2}{c|}{$\begin{array}{c}\text { Mass fraction of styrene in co- } \\
\text { polymer }\end{array}$} \\
\cline { 2 - 5 } & MMA & Styrene & PMR method & FT- IR method \\
\hline P-1 & 1 & - & - & - \\
\hline P-2 & 0.975 & 0.025 & 0.012 & 0.013 \\
\hline P-3 & 0.950 & 0.050 & 0.024 & 0.025 \\
\hline P-4 & 0.925 & 0.075 & 0.038 & 0.033 \\
\hline P-5 & 0.900 & 0.100 & 0.049 & 0.051 \\
\hline
\end{tabular}

\subsection{Effect of Styrene Incorporation}

The comparison of SSI results (Table 2) indicated that PSSI values of copolymer are greater than homopolymer. It is also observed that PSSI of copolymer gradually increases with increase in styrene concentration in the feed of copolymerization mixture. A comparison of SSI among the copolymers studied, shows that there is a linear relationship between SSI and \% of styrene in the copolymer. These suggest that styrene incorporation in the acrylate chain has a strong influence on the viscosity of the polymer - solvent blend (Figure.1).
Table 2. Physical parameters of Polymeric Sample

\begin{tabular}{ccccc}
\hline Sample & {$[\eta]_{\mathrm{h}}$} & $\mathrm{M}_{\mathrm{h}} \times 10^{-4}$ & PVL & PSSI \\
\hline P-1 & 7.69 & 3.54 & 25.93 & 27.65 \\
P-2 & 6.32 & 2.70 & 51.02 & 26.98 \\
P-3 & 13.5 & 7.69 & 49.43 & 53.00 \\
P-4 & 14.4 & 8.41 & 74.44 & 54.38 \\
P-5 & 15.12 & 8.99 & 25.66 & 77.00 \\
\hline
\end{tabular}

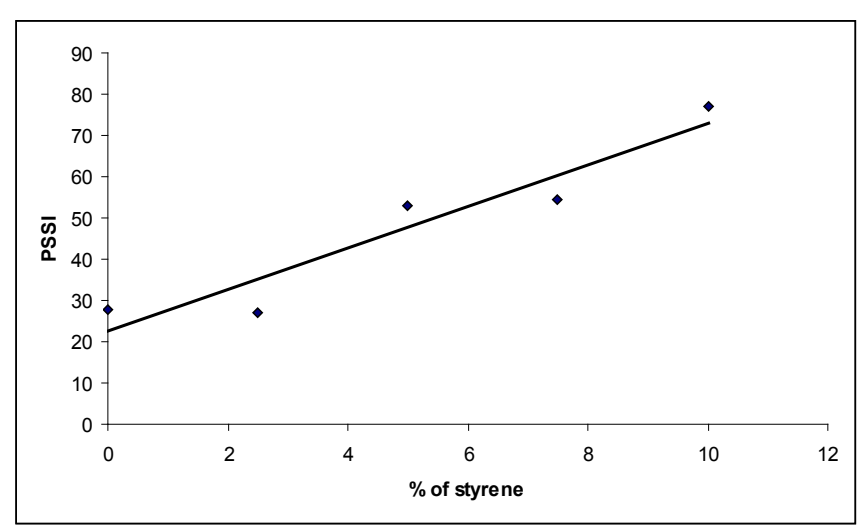

Figure 1. Plot of $\%$ of styrene in copolymer with PSSI

\subsection{Effect of Polymer Molecular Weight / Intrinsic Viscosity}

It is observed that SSI values of the copolymers (except P-2) are higher compare to the homopolymer (Table 2) and there is a gradual increase of these values of the copolymer with the increase in styrene concentration in the feed of copolymerization mixture. It is also observed maximum SSI value is obtained for the copolymer with maximum styrene concentration in the feed. This may be explained on the basis of molecular weight of the polymer. The higher mol. wt. and narrow mol weight distribution can provide relatively a higher molecular mass to undergo degradation with increase in polymer concentration than in the case of poly(methyl methacrylate) or copolymer with relatively lower mol. weight.

The intrinsic viscosity data (Table 2) also indicated higher molecular size for the copolymer compared to PMMA. It is reported that styrene copolymers exhibited aggregated structure in solvents[15.16]. This phenomenon is expected to play a significant role in determining the shear stability of copolymer with styrene.

\subsection{Evaluation of Thickening Property in Toluene Solvent}

Thickening behavior of the polymers in toluene solvent has been determined and the results are presented in Table 3. The data generated (Table 3 ) for the entire polymer solutions have been compared. It revealed that although thickening performance of the polymers, both the homopolymer and copolymers, is higher at a higher concentration but the data could not yield any correlation of thickening properties among the homo and copolymers as well as among the copolymers with different extent of styrene concentrations in them. This is consistent with our earlier observation[1]. 
Table 3. Thickening power and kinematic viscosity data

\begin{tabular}{|c|c|c|c|c|}
\hline Sample & Conc. $\left(\mathrm{g} . \mathrm{cm}^{-1}\right)$ & $\begin{array}{c}\text { Kinematic } \\
\text { Viscosity }\end{array}$ & $\begin{array}{c}\text { Increase in } \\
\text { viscosity }\end{array}$ & Thickening \\
\hline Solvent & - & 0.451 & - & - \\
\hline P-1 & 0.0605 & 0.783 & 0.332 & 2.00 \\
\hline & 0.0454 & 0.695 & 0.224 & 1.10 \\
\hline P-2 & 0.0605 & 0.806 & 0.355 & 2.15 \\
\hline & 0.0454 & 0.629 & 0.178 & 0.808 \\
\hline P-3 & 0.0605 & 0.886 & 0.435 & 2.63 \\
\hline & 0.0454 & 0.779 & 0.328 & 1.49 \\
\hline P-4 & 0.0605 & 0.788 & 0.337 & 2.04 \\
\hline & 0.0454 & 0.689 & 0.238 & 1.08 \\
\hline P-5 & 0.0605 & 0.893 & 0.442 & 2.67 \\
\hline & 0.0454 & 0.770 & 0.319 & 1.45 \\
\hline
\end{tabular}

3.5. Performance of the Homo and Copolymers as PPD in Base Oils

Table 4. Properties of Base oils

\begin{tabular}{|c|c|c|c|c|c|c|}
\hline $\begin{array}{c}\text { Base oil } \\
\text { properties }\end{array}$ & \multicolumn{6}{|c|}{ Base oil } \\
\hline & \multicolumn{2}{|c|}{$\mathrm{B} 1$} & \multicolumn{2}{c|}{ B2 } & \multicolumn{2}{c|}{ B3 } \\
\hline & $\mathrm{A}$ & $\mathrm{B}$ & $\mathrm{A}$ & $\mathrm{B}$ & $\mathrm{A}$ & $\mathrm{B}$ \\
\hline $\begin{array}{c}\text { Density } \\
\left(\mathrm{g} . \mathrm{cm}^{-3}\right) \text { at } \\
40^{0} \mathrm{C}\end{array}$ & 0.85 & 0.89 & 0.90 & 0.93 & 0.98 & 0.97 \\
\hline $\begin{array}{c}\text { Viscosity at } \\
40^{\circ} \mathrm{C} \text { in cSt }\end{array}$ & 7.47 & 8.01 & 20.25 & 21.00 & 112.05 & 112.80 \\
\hline $\begin{array}{c}\text { Viscosity at } \\
100^{\circ} \mathrm{C} \text { in } \\
\mathrm{cSt}\end{array}$ & 3.52 & 3.81 & 5.54 & 5.79 & 10.82 & 11.33 \\
\hline $\begin{array}{c}\text { Cloud point, } \\
{ }^{0} \mathrm{C}\end{array}$ & -8 & -8 & -10 & -10 & -6 & -6 \\
\hline $\begin{array}{c}\text { Pour point, } \\
{ }^{0} \mathrm{C}\end{array}$ & -3 & -3 & -6 & -6 & 0 & 0 \\
\hline
\end{tabular}

Table 5. Pour Point of additive doped Base oils

\begin{tabular}{|c|c|c|c|c|c|c|c|}
\hline \multirow[t]{3}{*}{ Base oil } & \multirow[t]{3}{*}{$\begin{array}{c}\text { PPD } \\
\text { Sample }\end{array}$} & \multicolumn{6}{|c|}{$\begin{array}{c}\text { Pour Point }\left({ }^{0} \mathrm{C}\right) \text { of base oils containing dif- } \\
\text { ferent } \%(\mathrm{~W} / \mathrm{W}) \text { of PPD }\end{array}$} \\
\hline & & \multicolumn{2}{|c|}{0.025} & \multicolumn{2}{|c|}{0.05} & \multicolumn{2}{|c|}{0.10} \\
\hline & & A & B & A & B & A & B \\
\hline \multirow{5}{*}{ B1 } & P-1 & -9 & -9 & -9 & -9 & -9 & -9 \\
\hline & P-2 & -12 & -12 & -15 & -15 & -15 & -15 \\
\hline & P-3 & -12 & -15 & -18 & -18 & -18 & -18 \\
\hline & P-4 & -15 & -15 & -15 & -18 & -21 & -21 \\
\hline & P-5 & -12 & -12 & -18 & -18 & -18 & -21 \\
\hline \multirow{5}{*}{ B2 } & P-1 & -9 & -9 & -12 & -9 & -12 & -12 \\
\hline & P-2 & -15 & -15 & -15 & -15 & -15 & -15 \\
\hline & P-3 & -18 & -18 & -18 & -18 & -18 & -18 \\
\hline & P-4 & -18 & -21 & -18 & -18 & -21 & -18 \\
\hline & P-5 & -21 & -24 & -21 & -18 & -24 & -21 \\
\hline \multirow{5}{*}{ B3 } & P-1 & -6 & -6 & -9 & -12 & -12 & -12 \\
\hline & P-2 & -12 & -12 & -12 & -15 & -15 & -15 \\
\hline & P-3 & -15 & -15 & -15 & -18 & -18 & -18 \\
\hline & P-4 & -18 & -15 & -15 & -15 & -18 & -18 \\
\hline & P-5 & -18 & -18 & -15 & -18 & -21 & -18 \\
\hline
\end{tabular}

Base oil (lube oil) of three different viscosity grades (B1, B2 and B3) were used to study the PPD performance of the copolymers in comparison to the homopolymer. Properties of base oils were tabulated in Table 4 and pour point of the different levels of additive doped lube oils were tested and tabulated in Table 5. It indicated that the prepared copolymer samples are more efficient as pour point depressant than the homo polymer and the efficiency increases with the increase in concentration of additive up to a certain limit.

\section{Conclusions}

The study indicated that the PSSI values of copolymer are greater than homopolymer and increased gradually with the increase in styrene concentration in the feed of copolymerization mixture. PPD performance of the additive doped base oils also followed the similar trend

These suggest that styrene incorporation in the acrylate chain has a strong influence on the shear stability of the polyacrylate type of additives. Molecular weight of the acrylate-styrene copolymer is directly proportional to their shear stability Incorporation of styrene raises the molecular size of the copolymer, as is evident from the intrinsic viscosity data. There is no correlation of thickening properties among the homo and copolymers as well as among the copolymers with different extent of styrene concentrations in them.

\section{ACKNOWLEDGEMENTS}

Thanks are due to University Grants Commission, New Delhi for financial assistance and to IOCL and BPCL for supplying the base oils used in the investigation.

\section{REFERENCES}

[1] Ghosh, P., Pantar, A. V., and Sarma, A. S. 1998, Ind. J. Chem. Tech. 5, 371-375

[2] Ghosh, P., Das, T. and Nandi, D. 2009, Synthsis of Copolymers and Homopolymers of Methyl Methacrylate and Styrene and Studies on their Viscometric Properties in Three Different Solvents. Research J. of Chem. and Envirn. 13(1), 17-25

[3] Abdel-Azim, A. A. A., Nasser, A. M., Ahmed, N. S., Kafrawy, A. F. E. I., Kamal, R. S.,2009, Petroleum Science and Technology 27, 20

[4] Schulz, D. N. \& Glass, J. E., 1991, Polymers as Rheology Modifiers, Amer Chem Soc, (Washington DC)

[5] Ferry, J. D.,1980, Viscoelastic Properties of Polymers, Wiley, (New York)

[6] Briant, J., Denis J., \& Parc, G., 1989, Rheology properties of Lubricants, Edition Technip, (Paris)

[7] Alexander, D. L. \& Rein, S. W., 1987, Relationship between engine oil bench shear stability tests, SAE paper No. 872047

[8] Alexander, D. L., Kapuscinski, M. M. \& Laffin, M. V., 1989, J. Lubri. Eng. 45, 80 
[9] Mortier, R. M., Qrszulik, S. T., 1997, Chemistry and Technology of Lubricants; Blackie Academic and Professiona. (London)

[10] Beyer, C., Jelitte, R., 1992, Lubr. Eng. 48, 450-453

[11] Bataille P., Sharifi-sajani, N.,and Evin E, 1994, J. Solution Che., 23 (2), 325-338

[12] Santos, J. C. O., Dos Santos, I. M. G., Souza, A. G., Sobrinho, E. V., Fernandes, Jr., V. J., and Silva, A. J. N. (2004), Thermoanalytical and rheological characterization of automotive mineral lubricants after thermal degradation, Fuel 83,
2393-2399

[13] Ghosh, P. Das, M., and Das, Tapan, (2010). Res. J. of Chem. and Envn. 14(4): 26-31

[14] Srivastava, D., 2003, Iranian Polym. J. 12(6): 449

[15] Ivana, I. M., Delpech, M. C., Coutinho, F. M. B., Albino, F. F. M., 2006, Viscometric Study of High-Cispolybutadiene in Toluene Solution. J. Braz. Chem. Soc., 12, 194-199

[16] Delpech, M. C., Coutinho, F. M. B., Habibe, M. E. S. (2002).Polym. Test. 21(4), 411-415 